\title{
'Steinstrasse' in biliary tree - MRCP appearance
}

\section{Nagarajan Krishnan}

Published online: 15 March 2012

(C) Indian Society of Gastroenterology 2012

A sixty-year-old man presented with obstructive jaundice and was evaluated by magnetic resonance cholangiopancreatography (MRCP). MRCP (Fig. 1) showed numerous calculi
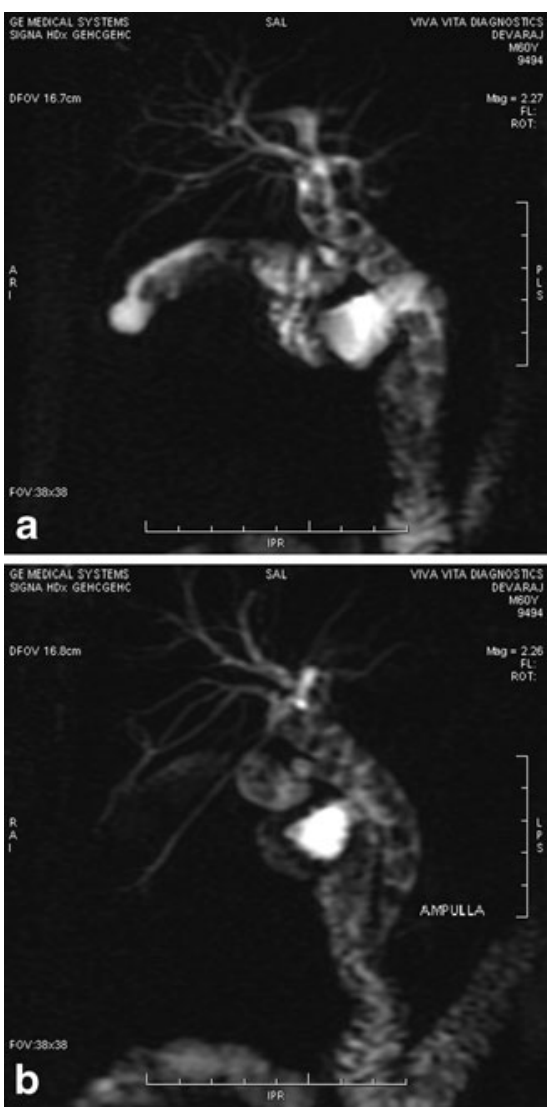

Fig. 1 a and b 3D MRCP (MIP) images show multiple hypointense calculi in gallbladder, cystic duct, left hepatic, common hepatic and common bile ducts with partial overlap of pylorus over the midcommon bile duct

N. Krishnan $(\bowtie)$

Sree Balaji Medical College and Hospital,

Works Road, Chrompet,

Chennai 600044, Tamil Nadu, India

e-mail: 1knagarajan@yahoo.co.in all along the entire biliary tree - the gallbladder, cystic duct, left hepatic, common hepatic and common bile ducts.

'Steinstrasse' is street of stones in German. It has been described in the urinary tract usually after fragmentation of renal pelvi-calyceal calculi by lithotripsy [1] and occasionally spontaneously [2].

\section{References}

1. Fedullo LM, Pollack HM, Banner MP, Amendola MA, Van Arsdalen $\mathrm{KN}$. The development of steinstrassen after ESWL: frequency, natural history, and radiologic management. AJR Am J Roentgenol. 1988;151:1145-7.

2. Van Savage JG, Fried FA. Bilateral spontaneous steinstrasse and nephrocalcinosis associated with distal renal tubular acidosis. J Urol. 1993;150:467-8. 